\title{
El control interno en la constatación física de existencias y bienes de larga duración del Gobierno Provincial de Manabí, año 2020
}

Internal control in the physical verification of stocks and long-lived assets of the Government Provincial de Manabí, year 2020

1 Yandry Rodolfo Reyna Delgado

Estudiante de la Maestría de Contabilidad y Auditoria, Instituto de Posgrado, Universidad Técnica de Manabí, Portoviejo, Ecuador yreyna0845@utm.edu.ec

2 María Fernanda Mendoza Saltos https://orcid.org/0000-0002-9518-8522

Docente de la Universidad Técnica de Manabí, Departamento de Contabilidad y Auditoría, Portoviejo, Ecuador. fernanda.mendoza@utm.edu.ec

Artículo de Investigación Científica y Tecnológica Enviado: $17 / 12 / 2021$

Revisado: $28 / 12 / 2021$

Aceptado: 28/01/2021

Publicado:05/02/2022

DOI: https://doi.org/10.33262/ap.v4i1.1.149

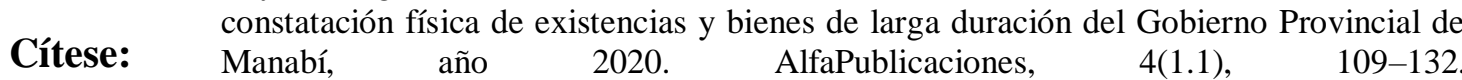
https://doi.org/10.33262/ap.v4i1.1.149

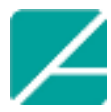

Ciencia Digital

ALFA PUBLICACIONES, es una Revista Multidisciplinar, Trimestral, que se publicará en soporte electrónico tiene como misión contribuir a la formación de profesionales competentes con visión humanística y crítica que sean capaces de exponer sus resultados investigativos y científicos en la misma medida que se promueva mediante su intervención cambios positivos en la sociedad. https://alfapublicaciones.com

La revista es editada por la Editorial Ciencia Digital (Editorial de prestigio registrada en la Cámara Ecuatoriana de Libro con No de Afiliación 663) www.celibro.org.ec

Esta revista está protegida bajo una licencia Creative Commons Attribution Non Commercial No Derivatives

4.0 International. Copia de la licencia: http://creativecommons.org/licenses/by-nc-nd/4.0/ 


\section{Palabras}

claves:

control interno, constatación

física, bienes de larga duración, inventarios, procedimientos.

\section{Keywords:}

internal control, physical verification, long-lived assets, inventories, procedures

\section{Resumen}

El control interno se ha convertido en una herramienta de mejora a lo largo de la historia institucional, puesto que se concibe como la adopción de políticas y procedimientos que regulan el flujo de las actividades, en este caso relacionadas con el inventario y bienes de larga duración, no se han encontrado investigaciones profundas en control interno relacionadas con la constatación física de inventarios y bienes de larga duración diseñadas por las instituciones, acogiéndose de este modo a la Normativa General. El objetivo consistió en analizar el control interno en la gestión de constatación física de inventarios y bienes de larga duración en el Gobierno Provincial de Manabí. La investigación fue mixta, no experimental, transeccional y descriptiva, apoyada en el método deductivo, también fue documental. Los resultados mostraron que el personal encargado de los inventarios, desconoce de procedimientos de constatación física de acuerdo a lo establecido en las Normas de Control Interno. Se realiza la constatación física de inventarios de manera periódica y de bienes de larga duración cada año. A partir de los resultados se diseñó el procedimiento para el manejo de inventarios que ha mejorado el flujo de actividades, definiendo los lineamientos que son de aplicabilidad. Se responsabilizó a los funcionarios involucrados en cada una de las actividades de conformidad con las Normas de Control Interno. También aportó en la mejora continua en la gestión de la constatación física de bienes de larga duración e inventarios. Se concluye que el control interno favorece la gestión de inventarios y bienes de larga duración con procedimientos para una clara percepción de efectividad, idoneidad y cumplimiento de las operaciones.

\section{Abstract}

Internal control has become a tool for improvement throughout institutional history, since it is conceived as the adoption of policies and procedures that regulate the flow of activities in this case related to inventory and long-lived assets, no in-depth research has been found on internal control related to the physical verification of inventories and long-lived assets designed by the institutions, thus complying with the General Regulations. The objective was to analyze internal control in the management of physical verification of inventories and long-lived assets in the Provincial Government 
of Manabí. The research was mixed, non-experimental, transactional and descriptive, based on the deductive method. The results showed that the personnel in charge of inventories are unaware of the physical verification procedures in accordance with the Internal Control Standards. Physical verification of inventories is performed periodically and of long-lived assets every year. There is organized information with stock details, which facilitates realtime visualization. Based on the results, the inventory management procedure was designed, which has improved the flow of activities, defining the guidelines that are applicable. The officers involved in each of the activities were made responsible in accordance with the Internal Control Standards. It also contributed to the continuous improvement in the management of the physical verification of long-lived assets and inventions. It is concluded that internal control favors the management of inventories and long-lived assets with procedures for a clear perception of effectiveness, suitability and compliance of operations.

\section{Introducción}

El control interno es una herramienta que permite medir el cumplimiento de las actividades a partir de la adopción de normas y procedimientos internos o externos. La administración de bienes y existencias (inventarios) comprende el conjunto de actividades relacionadas con estos activos en lo que respecta desde la contratación para la adquisición hasta la distribución para los fines institucionales en relación a la misión. Dentro de la administración de bienes de larga duración y existencias (inventarios), se encuentra el control interno por medio de la constatación física. En las instituciones del sector público estos procesos se encuentran regulados por normativa expedida por la Contraloría General del Estado, sin embargo, en ella no se evidencia el procedimiento detallado, por lo que se dispone que se adopten procedimientos internos para regular estas actividades.

Se ha reconocido a nivel mundial que la auditoría del sector público tiene un mandato más amplio que el de la fiscalización del sector privado; la INTOSAI debe definir los términos de auditoría gubernamental debido a las necesidades específicas de la fiscalización pública. Constituye un foro para que los auditores gubernamentales puedan debatir los temas de interés recíproco y mantenerse al tanto de los últimos avances en la fiscalización y de las otras normas profesionales y mejores prácticas que sean aplicables (Intosai, 2013, p.12). 
Las actividades de control hacen referencia a procedimientos que garantizan la administración y estos deben estar basados en políticas de control, estas últimas proceden de cada rincón de la empresa y se dejan para cada una de las funciones empresariales (Cherres, 2020).

La Real Academia Española (2020), define en su diccionario al control como: comprobación, inspección, fiscalización, intervención, y por otro lado también se define como: la actividad desarrollada por las administraciones públicas consistente en la verificación y vigilancia del cumplimiento de la legislación o de las exigencias establecidas en autorizaciones, licencias, concesiones y otros actos, mediante las que se habilita el ejercicio de actividades privadas.

En el campo de la administración el control es un elemento del proceso administrativo que incluye todas las actividades que se emprenden para garantizar que las operaciones reales coincidan con las operaciones planificadas (Urquizo, 2014). El control es una herramienta de especial importancia en la vida de una organización y especialmente en los procesos de gobierno (Ruiz \& Hernández, 2007).

El control interno proporciona seguridad razonable en la gestión de recursos. El desarrollo económico de los países ha evidenciado que una de las debilidades que enfrentan diferentes organizaciones es el vulnerable sistema de control interno que implementan, ya que este en la mayoría de los casos no ayuda a mitigar los riesgos a los que se ven expuestas y, peor aún, no sirve de herramienta para prever situaciones que afecten el negocio en marcha. Esta es una situación que se presenta en todos los entornos de los sectores económicos. En la historia, encontramos empresas que protagonizaron grandes escándalos financieros, como Enron, WorldCom, Parmalat, entre otras, que sacudieron la gestión y el control en las organizaciones y que dieron pie a que los cimientos del control interno fueran más sólidos (Firma Actualícese, 2017).

El Control Interno se define como una suma de procedimientos que deben ser llevados a cabo en las empresas con el fin de lograr las metas trazadas, buscando la confiabilidad en las operaciones administrativas, operativas o financieras minimizando el riesgo, velando por el cumplimiento de las normas y regulaciones (Vásquez, 2016. p.114).

En América se han desarrollado diferentes modelos de control a nivel para las empresas, para mejorar la dirección y directiva. Los modelos más conocidos son: el COSO (USA), el COCO (Canadá), el Cadbury (Reino Unido), el Vienot (Francia), el Peters (Holanda), King (Sudáfrica) y MICIL (adaptación del COSO para Latinoamérica). Los modelos COSO, COCO s y MICIL son los más adoptados en las empresas del continente americano (Rivas, 2011, p. 5). 
Mendoza \& Bayón (2019), indican que es muy importante tener en cuenta el control de las empresas y sus componentes garantizan: una adecuada información (precisa, oportuna, objetiva y completa, flexible, centrada en los puntos estratégicos de control y realista en lo económico y lo organizativo), protección de los recursos, la supervisión de las actividades, la evaluación del riesgo y el ambiente de control, y el control de las políticas (p.26).

En Iberoamérica diferentes organismos de cooperación internacional como el Banco Mundial (BM), el Fondo Monetario Internacional (FMI), la OCDE, entre otros, han venido acompañado a los países en sus procesos de democratización brindando lineamientos y marcos de referencia para que sean implementados y así promover su desarrollo. Un ejemplo es el de control interno en las organizaciones, el cual parte de prácticas del sector privado para promover la cultura del control estratégico, el autocontrol, la autoevaluación y la generación de información y comunicación en las entidades públicas (Montiel, 2017, p. 12).

En el ámbito del sector público, el sistema de control interno garantiza el cumplimiento de los objetivos, la protección y conservación del patrimonio, el acatamiento de la normativa legal prevista y la transparencia y oportunidad en la rendición de cuentas (Ablan \& Méndez, 2010, p.6).

El fraude y la corrupción, le han causado mal al patrimonio público. La globalización ha inducido al Estado a acelerar un proceso de fortalecimiento institucional de su gestión, en los planos técnico y político, el cual se logra al incorporar mejores prácticas de gestión que le permitan iniciar una transición de un Estado pre-moderno hacia un Estado posmoderno, eficiente, ágil, con capacidad de adaptación a los cambios y capaz de responder adecuadamente a las demandas sociales (Gamboa et al., 2016. p.500).

En el Ecuador, la Contraloría General del Estado emitió las Normas de Control Interno con la finalidad de normar el cumplimiento de actividades del sector público basadas en el informe COSO, y disponen a las entidades el diseño de procedimientos a través de la implementación de políticas internas.

El Control Interno bien aplicado contribuye fuertemente a obtener una gestión óptima, toda vez que genera beneficios a la administración de la entidad, en todos los niveles, así como en todos los procesos, sub procesos y actividades en donde se implemente (Mendoza et al., 2018, pp. 212-213).

Alana et al. (2017), expresan que para el diseño de un sistema de control interno efectivo la administración debe contar con: cumplimiento de la legislación; eficiencia y eficacia de las operaciones; y confiabilidad de los estados financieros (p. 146), razón por la cual 
se torna necesario el análisis del control interno en la administración de existencias y bienes de larga duración en el Gobierno Provincial de Manabí.

El control interno sobre los inventarios es importante. Las compañías exitosas tienen gran cuidado de proteger sus inventarios. El control interno hace referencia al conjunto de procedimientos de verificación automática que se producen por la coincidencia de los datos reportados por diversos departamentos o centros operativos. El control interno es de importancia para la estructura administrativa contable (Novo, 2016, p.36).

En la Norma Internacional de Información Financiera para pequeñas y medianas empresas se definen a los inventarios como activos: (a) poseídos para ser vendidos en el curso normal del negocio; (b) en proceso de producción con vistas a esa venta; o (c) en forma de materiales o suministros, para ser consumidos en el proceso de producción, o en la prestación de servicios (International Financial Reporting Standard for Small and Medium-Sized Entities, 2017, p.84).

En lo que se refiere a la propiedad, planta y equipo, la NIC 16 los define como "activos tangibles que: (a) posee una entidad para su uso en la producción o el suministro de bienes y servicios, para arrendarlos a terceros o para propósitos administrativos; y (b) se espera utilizar durante más de un periodo". (International Financial Reporting Standard for Small and Medium-Sized Entities, 2017)

Los inventarios son activos identificados como materiales o suministros consumibles durante el proceso de producción, en la prestación de servicios o conservados para la venta o distribución, en el curso ordinario de las operaciones. Son Inventarios:

- Los bienes comprados y mantenidos para revender

- Los terrenos y otros activos inmuebles mantenidos para la venta;

- Los bienes producidos terminados;

- Los materiales y suministros en espera de ser utilizados en el proceso productivo;

- Los bienes comprados o producidos por la entidad para ser distribuidos a terceros;

- Las obras en curso, destinadas a la venta o a la transferencia sin contraprestación a favor de terceros;

- Alimentos y productos agrícolas destinados a la venta o consumo en la etapa posterior al punto de la cosecha y recolección

- Municiones;

- Materiales consumibles;

- Materiales de mantenimiento;

- Piezas de repuesto de planta o equipo que no se tratan como Propiedad, Planta y Equipo 
- Suministros del servicio postal almacenados para la venta (Ministerio de Economía y Finanzas, 2016, p. 20).

Por otro lado, los bienes de control administrativo son bienes no consumibles de propiedad de la entidad u organismo, tendrán una vida útil superior a un año y serán utilizados en las actividades de la entidad, y los bienes de propiedad, planta y equipo son bienes destinados a las actividades de administración, producción, suministro de bienes, servicios y arrendamiento (Contraloría General del Estado, 2020).

En el Ecuador, la Contraloría General del Estado (2009), emitió las Normas de Control Interno para las entidades públicas, y en su marco normative relacionado con la Administración Financiera de Bienes e Inventarios referidos en el almacenamiento y distribución señala: "Para el control de los bienes se establecerá un sistema adecuado de registro permanente, debiendo incluirse registros auxiliares individualizados o por grupos de bienes de iguales características. Sólo las personas que laboran en el almacén o bodega tendrán acceso a las instalaciones".

La administración de cada entidad, emitirá los procedimientos necesarios a fin de realizar constataciones físicas periódicas de las existencias y bienes de larga duración. Se efectuarán constataciones físicas de las existencias y bienes de larga duración por lo menos una vez al año. El personal que interviene en la toma física, será independiente de aquel que tiene a su cargo el registro y manejo de los conceptos señalados, salvo para efectos de identificación.

Los procedimientos para la toma física de los bienes, se emitirán por escrito y serán formulados claramente de manera que puedan ser comprendidos fácilmente por el personal que participa en este proceso (Contraloría General del Estado, 2009).

En cada área de las entidades u organismos del sector público se efectuará la constatación física de los bienes e inventarios, por lo menos una vez al año, en el tercer trimestre de cada ejercicio fiscal, con el fin de: a) Confirmar su ubicación, localización, existencia real y la nómina de los responsables de su tenencia y conservación; b) Verificar el estado de los bienes (bueno, regular, malo); y, c) Establecer los bienes que están en uso o cuales se han dejado de usar. Los resultados de la constatación física serán enviados a la Unidad Administrativa para fines de consolidación (Contraloría General del Estado, 2020).

En virtud de lo antes expuesto, la investigación se fundamenta en que los controles y procedimientos establecidos han contribuido en la eficiencia, eficacia, efectividad y calidad institucional, convirtiéndose el control interno en un instrumento que norma el funcionamiento de las actividades en el sector público, y de esta manera determinar acciones a los funcionarios que permitan proveer cuidado y seguridad, uso, custodia y conservación sobre las existencias y bienes de larga duración. 
Por consiguiente, el objetivo de la investigación está referido al análisis del control interno en la constatación física de existencias y bienes de larga duración del Gobierno Provincial de Manabí, año 2020; que se fundamenta con el diagnóstico de la situación actual de la entidad referente a los procedimientos aplicados a la constatación física de bienes e inventarios, así como la descripción de los mismos como actividades realizadas, que faciliten de esta manera proponer acciones de acuerdo a los resultados y novedades de este proceso de control.

\section{Metodología}

Se concibe como la descripción detallada y precisa de las estrategias y procedimientos de cómo se va a realizar la investigación (Ponce et al., 2015). A partir de esta concepción se utilizó una investigación de enfoque mixto, porque representan un conjunto de procesos sistemáticos, empíricos y críticos de investigación e implican la recolección y el análisis de datos cuantitativos y cualitativos, así como su integración y discusión conjunta, para realizar inferencias producto de toda la información recabada y lograr un mayor entendimiento del fenómeno bajo estudio (Aguilar, 2016).

En cuanto al diseño de la investigación, es de carácter no experimental en estos diseños no se manipulan las variables, los fenómenos se observan de manera natural, para posteriormente analizarlos Arispe et al. (2020); transeccional porque son estudios que recolectan datos en un solo momento; y de tipo descriptiva, ya que en estos estudios se seleccionan una serie de cuestiones y se mide cada una de ellas en forma independiente Universidad San Martín (2020), y en este caso particular porque permitió describir detalladamente cada actividad referente al proceso de constatación física de bienes de larga duración e inventarios. Por otro lado, fue una investigación documental

Para la recolección de la información se tomó una población de 13 funcionarios, considerándose una población finita, así como lo afirma Fuente (2004) que "cuando se conoce el número de individuos que la componen, se habla de población finita". Fue un muestreo no probabilístico, donde la selección de los sujetos a estudio dependerá de ciertas características, criterios, etc. que él (los) investigador (es) considere (n) en ese momento (Otzen \& Manterola, 2017).

En total los actores son en un número menor a cincuenta, porque la población es igual a la muestra. En razón de que la población implicada es inferior a 100 personas, se aplicó el tipo de muestra no probabilística por conveniencia, en la que se tomaron todas las personas de la población, por contar con disponibilidad de acceso y por ser los actores que desarrollan directamente las actividades de producción.

Con relación a las técnicas de recolección de información se aplicaron la observación y la encuesta, y como instrumentos el cuestionario con 10 preguntas que contienen 
preguntas en la escala de Likert, y la guía de observación que recoge los procedimientos observados.

Adicionalmente, se realizó una investigación documental, tomada de datos y fuentes de información secundarias, que comprendió la revisión del archivo físico y análisis del informe de constatación física de bienes y del informe de constatación física de inventarios del año 2020 del Gobierno Provincial de Manabí y revisión de revistas científicas.

\section{Resultados y Discusión}

\section{Fase de campo}

\section{Bodegas físicas}

De la observación realizada se obtuvo como información que en lo que respecta a las existencias se encuentran físicamente almacenadas en bodegas dependiendo de la naturaleza de los bienes, entre ellas se encuentran: Bodega de Aceites y Lubricantes, Bodega de Existencias de repuestos, insumos y otros inventarios, Bodega de Desarrollo Social.

La Bodega de Aceites y Lubricantes almacena los tanques de aceites y grasas que son para uso exclusivo del parque automotor del Gobierno Provincial de Manabí. Esta bodega se encuentra custodiada bajo llaves y su acceso es únicamente para los funcionarios del área de Almacén General delegados para el despacho y control de éstos.

En la Bodega de Existencias de repuestos, insumos y otros inventarios, cuyo espacio es para almacenar los repuestos, insumos del parque automotor de la institución, así como también los suministros de oficina, aseo, vestuarios, lencerías, prendas de protección y seguridad para el personal y para inversión de los diferentes proyectos que realiza la institución a través de sus Direcciones, así como también los insumos químicos y orgánicos adquiridos para la prevención de covid-19 del personal de la institución.

La Bodega de Desarrollo Social fue creada mediante el Reglamento a la Ordenanza que regula los convenios de cooperación para las donaciones o asignaciones no reembolsables de recursos públicos exclusivamente para la ejecución de programas o proyectos de inversión en beneficio directo de los grupos de atención prioritaria de la provincia de Manabí, cuya misión es custodiar y controlar el despacho de las existencias destinados para ayudas técnicas y humanitarias realizadas por la Dirección de Desarrollo Social a través de proyectos de inversión. Entre los productos que se almacenan se encuentran medicinas, insumos químicos y orgánicos, insumos odontológicos, existencias para ayudas técnicas y humanitarias. Esta bodega se encuentra bajo la responsabilidad de un delegado de la Dirección de Desarrollo Social quien es responsable de los egresos, y 
devoluciones de las existencias antes mencionadas. Se encuentra en un ambiente adecuado y climatizado, cuya temperatura es medida con el higrómetro, y se cuenta con perchas que indican con rótulos el nombre del inventario y el lote. Los cartones se encuentran ubicados encimas de pallets de madera y con el apilamiento máximo según indica el fabricante del producto, entre cada percha existe una distancia de aproximadamente $80 \mathrm{cms}$ y $30 \mathrm{cms}$ de distancia de la pared a los cartones que se encuentran en los pallets a fin de evitar la humedad por efectos de lluvias u otro fenómeno, todo esto en cumplimiento a lo dispuesto en la Guía Médica de Fármacos del Ministerio de Salud Pública.

\section{Bodegas de control en el sistema informático contable}

La administración de bienes e inventarios se lleva en el sistema contable Olympo del proveedor POTECOLTELSA S.A, y contiene las siguientes bodegas de control de inventarios:

Bodega de Combustibles, esta bodega es virtual puesto que físicamente la institución no cuenta con reservorios que de acuerdo a la naturaleza del combustible permita mantenerlo. Está creada para el control del combustible que se despacha en las gasolineras con las que el Gobierno Provincial de Manabí tiene contrato. Se registra la cantidad entregada a los despachadores designados, quienes se encargan de despachar a los vehículos con orden de movilización y salvoconductos. Aquí se controlan 3 clases de combustibles: diesel industrial, diesel normal, gasolina extra.

Bodega General, es aquella que controla inventarios que por su naturaleza representan entrada y salida inmediata o aquellos que por su naturaleza no pueden ser almacenados, pero por cumplimiento de normativa deben ser registrados y controlados, tales como material pétreo, inventarios para donaciones por convenios, entre otros puntuales.

Bodega de Aceites y Lubricantes, muestra el control en existencias de los aceites y lubricantes para el parque automotor. Entre ellos están el aceite 15w40, SAE50, grasa industrial, y otros.

Bodega de Desarrollo Social, en ella se controla el movimiento de entradas, salidas y devoluciones de ayudas técnicas y humanitarias.

El método que se utiliza para el control de inventarios es el promedio ponderado en concordancia con lo señalado en el Acuerdo 067 del Ministerio de Finanzas que contiene la Normativa de Contabilidad Gubernamental, bajo el sistema de inventario permanente o perpetuo.

El personal de almacén general que son los analistas son los encargados de realizar los movimientos en el sistema Olympo para cada una de las Bodegas previa asignación de la 
responsable de almacén general. En la bodega de desarrollo social los egresos son realizados por el responsable de dicha bodega.

\section{Recurrencia de constatación física}

Para los inventarios la constatación física se realiza de manera periódica por muestras, y obligatoria una vez al año de manera integral. Para esta actividad participaron funcionarios independientes del registro y control de los inventarios.

En la bodega de desarrollo social en el año 2020 la constatación se realizó de manera concurrente, es decir 4 veces al año: en julio, en septiembre, en noviembre y en diciembre. En las otras Bodegas en septiembre de manera obligatoria.

\section{Almacenamiento de bienes de larga duración y sujetos de control administrativo}

En el sistema Olympo se administran en el módulo de activos fijos donde se le asigna un código a cada uno dependiendo de la naturaleza del mismo, y diferenciándolo por una característica principal como marca, modelo, serie, color. Cada bien tiene asignado un custodio responsable de su cuidado y conservación. Físicamente, estos bienes no se encuentran almacenados sino en el uso de las actividades administrativas u operativas de la institución, para lo cual el custodio se ha responsabilizado mediante acta.

Los bienes en estado malo son entregados a la unidad de almacén general con un informe técnico elaborado por el área técnica correspondiente, y cuya custodia está bajo la responsabilidad de un funcionario de dicha área.

Resultados de la encuesta aplicada a funcionarios del Departamento de Almacén General del Gobierno Provincial de Manabí

Con el fin de conocer el estado del control interno y el proceso de constatación física del Gobierno Provincial de Manabí, se realizó un cuestionario con preguntas cerradas de acuerdo a la escala de Likert:

\section{Tabla 1}

Tabulación de resultados de encuesta aplicada al personal de la Dirección Administrativa del Gobierno Provincial de Manabí

\begin{tabular}{|c|c|c|c|c|c|c|c|c|c|c|c|c|c|}
\hline \multirow[t]{2}{*}{ \# } & \multirow[t]{2}{*}{ PREGUNTA } & \multicolumn{2}{|c|}{$\begin{array}{l}\text { TOTALMENTE } \\
\text { DE ACUERDO }\end{array}$} & \multicolumn{2}{|c|}{$\begin{array}{c}\text { DE } \\
\text { ACUERDO }\end{array}$} & \multicolumn{2}{|c|}{ INDECISO } & \multicolumn{2}{|c|}{$\begin{array}{c}\text { EN } \\
\text { DESACUERDO }\end{array}$} & \multicolumn{2}{|c|}{$\begin{array}{c}\text { TOTALMENTE } \\
\text { EN } \\
\text { DESACUERDO }\end{array}$} & \multicolumn{2}{|c|}{ TOTAL } \\
\hline & & $\mathrm{f}$ & $\%$ & $\mathrm{f}$ & $\%$ & $\mathrm{f}$ & $\%$ & $\mathrm{f}$ & $\%$ & $\mathrm{f}$ & $\%$ & $f$ & $\%$ \\
\hline 1 & $\begin{array}{l}\text { ¿Considera usted } \\
\text { importante el control } \\
\text { interno como herramienta } \\
\text { de salvaguarda de los } \\
\text { activos de la institución? }\end{array}$ & 10 & $77 \%$ & 1 & $8 \%$ & 2 & $15 \%$ & & & & & 13 & $100 \%$ \\
\hline
\end{tabular}




\section{Tabla 1}

Tabulación de resultados de encuesta aplicada al personal de la Dirección Administrativa del Gobierno Provincial de Manabí (continuación)

\begin{tabular}{|c|c|c|c|c|c|c|c|c|c|c|c|c|c|}
\hline \multirow[t]{2}{*}{ \# } & \multirow[t]{2}{*}{ PREGUNTA } & \multicolumn{2}{|c|}{$\begin{array}{l}\text { TOTALMENTE } \\
\text { DE ACUERDO }\end{array}$} & \multicolumn{2}{|c|}{$\begin{array}{c}\text { DE } \\
\text { ACUERDO } \\
\end{array}$} & \multicolumn{2}{|c|}{ INDECISO } & \multicolumn{2}{|c|}{$\begin{array}{c}\text { EN } \\
\text { DESACUERDO }\end{array}$} & \multicolumn{2}{|c|}{$\begin{array}{c}\text { TOTALMENTE } \\
\text { EN } \\
\text { DESACUERDO } \\
\end{array}$} & \multicolumn{2}{|c|}{ TOTAL } \\
\hline & & $\mathrm{f}$ & $\%$ & $\mathrm{f}$ & $\%$ & $f$ & $\%$ & $\mathrm{f}$ & $\%$ & $f$ & $\%$ & $\mathrm{f}$ & $\%$ \\
\hline 2 & $\begin{array}{ll}\text { ¿Conoce } & \text { los } \\
\text { procedimientos } & \text { de } \\
\text { constatación física de } & \text { de } \\
\text { bienes e inventarios de } \\
\text { acuerdo a lo establecido en } \\
\text { las Normas de Control } \\
\text { Interno? }\end{array}$ & 3 & $23 \%$ & 1 & $8 \%$ & 1 & $8 \%$ & 2 & $15 \%$ & 6 & $46 \%$ & 13 & $100 \%$ \\
\hline 3 & $\begin{array}{l}\text { ¿Se cuentan y aplican con } \\
\text { políticas y procedimientos } \\
\text { internos adoptados para el } \\
\text { control de los bienes e } \\
\text { inventarios? }\end{array}$ & 1 & $8 \%$ & 1 & $8 \%$ & 1 & $8 \%$ & 2 & $15 \%$ & 8 & $62 \%$ & 13 & $100 \%$ \\
\hline 4 & $\begin{array}{l}\text { ¿Está de acuerdo con que } \\
\text { se realice periódicamente } \\
\text { la constatación física de } \\
\text { bienes e inventarios? }\end{array}$ & 9 & $69 \%$ & 2 & $15 \%$ & & & & & 2 & $15 \%$ & 13 & $100 \%$ \\
\hline 5 & $\begin{array}{lrr}\text { ¿Beneficiaría } & \text { a } & \text { la } \\
\text { institución y a } & \text { los } \\
\text { funcionarios de Almacén } \\
\text { General el diseño e } \\
\text { implementación de un } \\
\text { procedimiento } & & \text { y } \\
\text { lineamiento para } & \text { la } \\
\text { constatación física } & \text { de } \\
\text { bienes e inventarios? } & \\
\end{array}$ & 9 & $69 \%$ & 2 & $15 \%$ & & & & & 2 & $15 \%$ & 13 & $100 \%$ \\
\hline 6 & $\begin{array}{l}\text { ¿El control interno } \\
\text { favorece la gestión de } \\
\text { inventarios y bienes de } \\
\text { larga duración con } \\
\text { procedimientos para una } \\
\text { clara percepción de } \\
\text { efectividad, idoneidad y } \\
\text { cumplimiento de las } \\
\text { operaciones? }\end{array}$ & 9 & $69 \%$ & 2 & $15 \%$ & & & & & 2 & $15 \%$ & 13 & $100 \%$ \\
\hline 7 & $\begin{array}{l}\text { ¿Considera que deben } \\
\text { responsabilizarse a los } \\
\text { funcionarios en cada una } \\
\text { de las actividades de la } \\
\text { constatación física de } \\
\text { conformidad con las } \\
\text { Normas de Control } \\
\text { Interno? }\end{array}$ & $\begin{array}{l}1 \\
0\end{array}$ & $77 \%$ & 2 & $15 \%$ & 1 & $8 \%$ & & & & & 13 & $100 \%$ \\
\hline
\end{tabular}


Tabla 1

Tabulación de resultados de encuesta aplicada al personal de la Dirección Administrativa del Gobierno Provincial de Manabí (continuación)

\begin{tabular}{|c|c|c|c|c|c|c|c|c|c|c|c|c|c|}
\hline \multirow[t]{2}{*}{ \# } & \multirow[t]{2}{*}{ PREGUNTA } & \multicolumn{2}{|c|}{$\begin{array}{l}\text { TOTALMENTE } \\
\text { DE ACUERDO }\end{array}$} & \multicolumn{2}{|c|}{$\begin{array}{c}\text { DE } \\
\text { ACUERDO } \\
\end{array}$} & \multicolumn{2}{|c|}{ INDECISO } & \multicolumn{2}{|c|}{$\begin{array}{c}\text { EN } \\
\text { DESACUERDO }\end{array}$} & \multicolumn{2}{|c|}{$\begin{array}{c}\text { TOTALMENTE } \\
\text { EN } \\
\text { DESACUERDO }\end{array}$} & \multicolumn{2}{|c|}{ TOTAL } \\
\hline & & $\mathrm{f}$ & $\%$ & $\mathrm{f}$ & $\%$ & $\mathrm{f}$ & $\%$ & $\mathrm{f}$ & $\%$ & $\mathrm{f}$ & $\%$ & $\mathrm{f}$ & $\%$ \\
\hline 8 & $\begin{array}{l}\text { ¿Con qué frecuencia } \\
\text { considera que se deben } \\
\text { reportar el detalle de } \\
\text { ingresos y egresos de } \\
\text { existencias a la Dirección } \\
\text { Financiera? }\end{array}$ & 9 & $69 \%$ & 4 & $31 \%$ & & & & & & & 13 & $100 \%$ \\
\hline 9 & $\begin{array}{l}\text { ¿Está de acuerdo que el } \\
\text { método de valoración de } \\
\text { existencias promedio } \\
\text { ponderado señalado en la } \\
\text { normativa de contabilidad } \\
\text { gubernamental es el } \\
\text { adecuado? }\end{array}$ & 9 & $69 \%$ & 4 & $31 \%$ & & & & & & & 13 & $100 \%$ \\
\hline 10 & $\begin{array}{l}\text { ¿Está de acuerdo con los } \\
\text { años de vida útil de los } \\
\text { bienes de larga duración } \\
\text { señalados en la normativa } \\
\text { de contabilidad } \\
\text { gubernamental? }\end{array}$ & 7 & $54 \%$ & 6 & $46 \%$ & & & & & & & 13 & $100 \%$ \\
\hline 11 & $\begin{array}{l}\text { ¿Durante su permanencia } \\
\text { en la institución se han } \\
\text { efectuado procedimientos, } \\
\text { indicadores, instructivos } \\
\text { para el proceso de } \\
\text { constatación física de } \\
\text { bienes e inventarios? }\end{array}$ & & & & & 2 & $15 \%$ & 8 & $62 \%$ & 3 & $\begin{array}{r}23 \\
\%\end{array}$ & 13 & $100 \%$ \\
\hline
\end{tabular}

Fuente: Personal de la Dirección Administrativa del Gobierno Provincial de Manabí

Los resultados del cuestionario aplicado muestran lo siguiente:

- Importancia del control interno: De las personas encuestadas, el $77 \%$ consideran totalmente de acuerdo el control interno como una herramienta para salvaguardar los activos de la institución.

- Conocimientos de procedimientos de constatación física de bienes e inventarios: El 46\% de los funcionarios encuestados están totalmente en desacuerdo que conocen los procedimientos de constatación física de bienes e inventarios de acuerdo a lo establecido en las Normas de Control Interno.

- Adopción de políticas y procedimientos internos: El 62\% de los encuestados indicaron que están en total desacuerdo que cuentan y aplican políticas y procedimientos internos adoptados para el control de los bienes e inventarios. 
- Recurrencia de la constatación física: De los encuestados el 69\% consideran totalmente de acuerdo que la constatación física de bienes e inventarios se realice de manera recurrente y periódica.

- Diseño e implementación de procedimientos de control interno: Se obtuvo como respuesta que el $69 \%$ está totalmente de acuerdo que se diseñen e implementen procedimientos para el proceso de constatación física de bienes e inventarios.

- Control interno y efectividad, idoneidad y cumplimiento de las operaciones: El 69\% de los encuestados indicaron que consideran totalmente de acuerdo que el control interno favorece la gestión de inventarios y bienes de larga duración con procedimientos para una clara percepción de efectividad, idoneidad y cumplimiento de las operaciones.

- Responsabilidad de funcionarios en el proceso de constatación física: El 77\% de los servidores encuestados consideran totalmente de acuerdo que deben responsabilizarse a los funcionarios intervinientes en cada una de las actividades de la constatación física de conformidad con las Normas de Control Interno.

- Reporte de ingresos y egresos a la Dirección Financiera: El 69\% de los encuestados indicaron que están totalmente de acuerdo que sea muy frecuente, el envío de reportes de ingresos y egresos a la Dirección Financiera, mientras que el $31 \%$ indicaron que sea frecuentemente.

- Método de valoración de inventarios: El 69\% de los encuestados indicaron que están totalmente de acuerdo con el método promedio para la valoración de los inventarios.

- Años de vida útil de los bienes de larga duración: Al respecto, el 54\% de los encuestados indicaron que consideran totalmente de acuerdo los años de vida útil de los bienes de larga duración señalados en la normativa.

- Procedimientos, indicadores, instructivos para constatación física: El 62\% indicaron que están en desacuerdo sobre el diseño de procedimientos, indicadores, instructivos para el proceso de constatación física de bienes e inventarios.

\section{Fase documental}

Los informes de constatación física de bienes de larga duración y sujetos de control administrativo, y de existencias del año 2020 no contaron con un procedimiento para realizar esta actividad de control, sino con un plan de trabajo y un cronograma tomando consideraciones de la normativa general. El corte de la constatación fue el 31 de julio de 2020. El departamento de Almacén General realizó un levantamiento de información de los bienes de larga duración, sujetos de control administrativo y existencias con corte al 31 de julio de 2020 sujetos a control de constatación física en el Gobierno Provincial de 
Manabí, así como los espacios físicos en los que se encuentran los bienes e inventarios sujetos a verificación física.

La tabla 2, muestra las cantidades y valores monetarios de bienes de larga duración y sujetos de control administrativos levantados que se sujetan a verificación física

Tabla 2

Detalle de bienes de larga duración y sujetos de control administrativo sujetos a constatación física del Gobierno Provincial de Manabí

\begin{tabular}{lrrr}
\hline \multicolumn{1}{c}{ Tipo de bienes } & $\begin{array}{c}\text { Costo histórico al } \\
\text { 31 de julio de 2020 }\end{array}$ & No. De ítems & $\begin{array}{c}\text { Porcentaje de } \\
\text { muestra } \\
\text { seleccionada }\end{array}$ \\
\hline Bienes de larga duración & & 3 & $100 \%$ \\
Edificios, locales y residencias & $610.167,53$ & 1037 & $100 \%$ \\
Equipos, sistemas y paquetes informáticos & $1.070 .658,54$ & 736 & $100 \%$ \\
Herramientas & $621.052,44$ & 390 & $100 \%$ \\
Libros y colecciones & $88.961,55$ & 1337 & $100 \%$ \\
Maquinarias y equipos & $34.935 .169,10$ & 2482 & $100 \%$ \\
Mobiliarios & $926.619,89$ & 17 & $100 \%$ \\
Partes y repuestos & $515.357,60$ & 173 & $100 \%$ \\
Terrenos & $756.208,12$ & 6182 & $100 \%$ \\
Vehículos & $8.305 .609,22$ & & \\
\multicolumn{1}{c}{ Suman } & $47.829 .803,99$ & 10 & $100 \%$ \\
\hline \multicolumn{1}{c}{ Suman } & Bienes sujetos de control administrativo & & $100 \%$ \\
\hline Bienes artísticos y culturales & $1.670,00$ & 740 & $100 \%$ \\
Equipos, sistemas y paquetes informáticos & $8.129,63$ & 297 & $100 \%$ \\
Herramientas & $38.322,17$ & 455 & $100 \%$ \\
Libros y colecciones & $9.208,30$ & 647 & $100 \%$ \\
Maquinarias y equipos & $16.997,62$ & 2358 & \\
Mobiliarios & $40.627,65$ & & \\
& $114.955,37$ & & \\
\hline
\end{tabular}

Fuente: Departamento de Almacén General del Gobierno Provincial de Manabí

En la tabla 3, se muestra el detalle de las existencias sujetas a verificación por bodega de almacenamiento de acuerdo al sistema Olympo. En este detalle se compilan los totales de ítems por bodega y el costo de inversión o corriente dependiendo de la asignación presupuestaria y de los fines del Gobierno Provincial de Manabí de acuerdo a los proyectos y programas que ejecuta a través de las Direcciones. 


\section{Tabla 3}

Detalle de existencias por bodegas sujetas a constatación física del Gobierno Provincial de Manabí

\begin{tabular}{|c|c|c|c|c|c|c|}
\hline \multirow{2}{*}{ DESCRIPCIÓN } & \multicolumn{2}{|c|}{ CONSUMO } & \multicolumn{2}{|c|}{ INVERSIÓN } & \multicolumn{2}{|c|}{ TOTAL } \\
\hline & USD & CANTIDAD & USD & CANTIDAD & USD & CANTIDAD \\
\hline $\begin{array}{l}\text { Bodega de } \\
\text { Existencias }\end{array}$ & $4,451.14$ & 2775 & $4,731,850.07$ & 45827 & $4,736,301.21$ & 48602 \\
\hline $\begin{array}{l}\text { Bodega de } \\
\text { Medicinas }\end{array}$ & $133,383.63$ & 107371 & - & 0 & $133,383.63$ & 107371 \\
\hline Bodega de & & & & & & \\
\hline $\begin{array}{l}\text { Aceites y } \\
\text { Lubricantes }\end{array}$ & - & 0 & $42,240.60$ & 16996.8 & $42,240.60$ & 16996.8 \\
\hline $\begin{array}{l}\text { Bodega de } \\
\text { Combustibles }\end{array}$ & - & 0 & $157,761.07$ & 113473 & $157,761.07$ & 113473 \\
\hline Bodega General & - & 0 & 255.36 & 3 & 255.36 & 3 \\
\hline SUMAN & $137,834.77$ & 110146 & $4,932,107.10$ & 176299.8 & $5,069,941.87$ & 286445.8 \\
\hline
\end{tabular}

La tabla 4, muestra los espacios físicos objetos de constatación de los bienes de larga duración, sujetos de control administrativo y existencias del Gobierno Provincial de Manabí. En esta tabla se muestran espacios de propiedad de la institución y arriendos.

\section{Tabla 4}

Detalle de espacios físicos sujetas a constatación física del Gobierno Provincial de Manabí

\begin{tabular}{lll}
\hline Objeto de constatación & \multicolumn{1}{c}{ Instalaciones } & \multicolumn{1}{c}{ Ubicación } \\
\hline & Edificio principal & Portoviejo, calle Córdova y Ricaurte \\
& Patio de Maquinarias & Portoviejo, Prolongación calle Pedro y Vicente \\
& Edificio La Estantilla & Céliz \\
& Cantón Chone & -) Parroquia Canuto \\
& Parroquia Crucita & -) Represa La Esperanza, sin Bocal Chone \\
Bienes de larga & Sector La Boca \\
duración y sujetos de & Portoviejo & -) Edificio Lozada Alvarado \\
control administrativo & & - -) Edificio Banco la Previsora \\
& & - -) Bodega ubicada en el patio de máquinas \\
& Portoviejo & -) Bodegas (5) ubicadas en la vía Portoviejo \\
& & Manta \\
& & - -) Varios talleres mecánicos donde están vehículos \\
& & en reparación \\
Cantón Pedernales & Oficina de atención al público (instalaciones del \\
consumo corriente e & GAD) \\
inversión & Patio de Maquinarias & Sector Machalilla \\
\hline
\end{tabular}

Fuente: Departamento de Almacén General del Gobierno Provincial de Manabí 
Participó el auditor interno en calidad de delegado de la Unidad de Auditoría Interna a la observación de los procedimientos aplicados a la toma física de bienes e inventarios.

En cuanto a los delegados verificadores, participaron funcionarios independientes del registro y control de los bienes e inventarios, delegados por las direcciones: Administrativa, Desarrollo Social, Participación Ciudadana, Planificación. Se capacitó a estos funcionarios para lo cual se firmó el acta de inicio de la ejecución de dicho proceso.

Se constataron 5668 bienes de larga duración de un total de 6182 registrados, y 1693 sujetos de control de 2358 registrados, los resultados se muestran en las tablas 5 y 6 .

\section{Tabla 5}

\section{Resultados de la constatación de bienes de larga duración}

\begin{tabular}{|c|c|c|c|c|}
\hline Cantidad & $\begin{array}{l}\text { Código del } \\
\text { bien }\end{array}$ & Descripción del bien & Estado & Costo histórico \\
\hline 3 & 002 & $\begin{array}{l}\text { Edificios, locales y } \\
\text { residencias }\end{array}$ & $\begin{array}{l}\text { Se detallan en las hojas de } \\
\text { verificación }\end{array}$ & $610.167,53$ \\
\hline 1004 & 007 & $\begin{array}{l}\text { Equipos, sistemas y } \\
\text { paquetes informáticos }\end{array}$ & $\begin{array}{l}\text { Se detallan en las hojas de } \\
\text { verificación }\end{array}$ & $1.043 .864,29$ \\
\hline 723 & 006 & Herramientas & $\begin{array}{l}\text { Se detallan en las hojas de } \\
\text { verificación }\end{array}$ & $618.531,66$ \\
\hline 390 & 009 & Libros y colecciones & $\begin{array}{l}\text { Se detallan en las hojas de } \\
\text { verificación }\end{array}$ & $88.961,55$ \\
\hline 1195 & 004 & Maquinarias y equipos & $\begin{array}{l}\text { Se detallan en las hojas de } \\
\text { verificación }\end{array}$ & $34.863 .232,65$ \\
\hline 2161 & 003 & Mobiliarios & $\begin{array}{l}\text { Se detallan en las hojas de } \\
\text { verificación }\end{array}$ & $834.182,54$ \\
\hline 17 & 011 & Partes y repuestos & $\begin{array}{l}\text { Se detallan en las hojas de } \\
\text { verificación }\end{array}$ & $515.357,60$ \\
\hline 2 & 001 & Terrenos & $\begin{array}{l}\text { Se detallan en las hojas de } \\
\text { verificación }\end{array}$ & $756.208,12$ \\
\hline 173 & 005 & Vehículos & $\begin{array}{l}\text { Se detallan en las hojas de } \\
\text { verificación }\end{array}$ & $8.305 .609,22$ \\
\hline \multicolumn{4}{|c|}{ Saldo según constatación física } & $47.636 .115,16$ \\
\hline & \multicolumn{3}{|c|}{ Saldo certificado al 31-07-2020 } & $47.829 .803,97$ \\
\hline & \multicolumn{3}{|c|}{ Diferencia } & $-193.688,81$ \\
\hline
\end{tabular}

Fuente: Departamento de Almacén General del Gobierno Provincial de Manabí

A la cantidad de cuarenta y siete millones seiscientos treinta y seis mil cientos quince con 16/100, USD. 47.636.115,16 asciende el valor constatado en la cuenta de bienes de larga duración, y que no concilia con el saldo contable a la fecha de corte 31 de julio de 2020, 
por una diferencia faltante de ciento noventa y tres mil seiscientos ochenta y ocho con 81/100, USD 193.688,81.

\section{Tabla 6}

Resultados de la constatación de bienes sujetos de control administrativo

Fuente: Departamento de Almacén General del Gobierno Provincial de Manabí

\begin{tabular}{|c|c|c|c|c|}
\hline Cantidad & $\begin{array}{l}\text { Código del } \\
\text { bien }\end{array}$ & Descripción del bien & Estado & Costo histórico \\
\hline 10 & 600 & $\begin{array}{l}\text { Bienes artísticos y } \\
\text { culturales }\end{array}$ & $\begin{array}{l}\text { Se detallan en las hojas de } \\
\text { verificación }\end{array}$ & $1.670,00$ \\
\hline 184 & 500 & $\begin{array}{l}\text { Equipos, sistemas y } \\
\text { paquetes informáticos }\end{array}$ & $\begin{array}{l}\text { Se detallan en las hojas de } \\
\text { verificación }\end{array}$ & $7.380,21$ \\
\hline 719 & 400 & Herramientas & $\begin{array}{l}\text { Se detallan en las hojas de } \\
\text { verificación }\end{array}$ & $37.483,44$ \\
\hline 296 & 700 & Libros y colecciones & $\begin{array}{l}\text { Se detallan en las hojas de } \\
\text { verificación }\end{array}$ & $9.191,30$ \\
\hline 434 & 200 & $\begin{array}{l}\text { Maquinarias y } \\
\text { equipos }\end{array}$ & $\begin{array}{l}\text { Se detallan en las hojas de } \\
\text { verificación }\end{array}$ & $16.305,44$ \\
\hline 509 & 100 & Mobiliarios & $\begin{array}{l}\text { Se detallan en las hojas de } \\
\text { verificación }\end{array}$ & $32.352,67$ \\
\hline & & \multicolumn{2}{|c|}{ Saldo según constatación física } & $104.383,06$ \\
\hline & & \multicolumn{2}{|c|}{ Saldo certificado al 31-07-2020 } & $114.955,37$ \\
\hline & & Diferencia & & $-10.572,31$ \\
\hline
\end{tabular}

A la cantidad de ciento cuatro mil trescientos ochenta y tres con 06/100, USD. 104,383.06 asciende el valor constatado en la cuenta de bienes sujetos de control, y que no concilia con el saldo contable a la fecha de corte 31 de julio de 2020, por una diferencia faltante de diez mil quinientos setenta y dos con 31/100, USD 10,572.31.

Los bienes que se encuentran en mal estado producto de la verificación, únicamente los pertenecientes al rubro "equipos, sistemas y paquetes informáticos" que cuentan con el informe técnico del área de tecnología. Las maquinarias fueron revisadas, y mediante la toma de improntas por el delegado de la unidad de mantenimiento se les verificó la serie del motor y el estado, cuyo informe fue realizado por la unidad antes mencionada indicando el estado, de las cuales 24 se consideraron "malas" y deben ser dadas de baja.

Constatados las existencias de inventarios por bodegas de ubicación, se establecen en la tabla 7: 


\section{Tabla 7}

Resultados de la constatación de existencias

\begin{tabular}{|c|c|c|c|c|c|c|}
\hline \multicolumn{2}{|c|}{ SUJETO A VERIFICAR } & \multirow{3}{*}{$\begin{array}{c}\text { DESCRIPCIÓN } \\
\text { DEL BIEN }\end{array}$} & \multicolumn{2}{|c|}{ VERIFICADO } & \multicolumn{2}{|c|}{ DIFERENCIAS } \\
\hline CANTIDAD & VALORES & & CANTIDAD & VALORES & CANTIDAD & VALORES \\
\hline A & B & & $\mathrm{C}$ & $\mathrm{D}$ & $\mathrm{E}=\mathrm{A}-\mathrm{C}$ & $F=B-D$ \\
\hline $48.602,00$ & $4.736 .301,49$ & $\begin{array}{l}\text { BODEGA DE } \\
\text { EXISTENCIAS }\end{array}$ & $48.638,00$ & $4.734 .497,15$ & $-36,00$ & $1.804,34$ \\
\hline $107.371,00$ & $133.383,63$ & $\begin{array}{l}\text { BODEGA DE } \\
\text { MEDICINAS }\end{array}$ & $107.371,00$ & $133.383,63$ & - & - \\
\hline & & BODEGA DE & & & & \\
\hline $16.996,80$ & $42.240,60$ & ACEITES Y & $16.996,80$ & $42.240,60$ & - & - \\
\hline & & LUBRICANTES & & & & \\
\hline $113.473,00$ & $157.761,07$ & $\begin{array}{l}\text { BODEGA DE } \\
\text { COMBUSTIBLES }\end{array}$ & $112.586,00$ & $155.812,62$ & 887,00 & $1.948,45$ \\
\hline 3,00 & 255,36 & $\begin{array}{l}\text { BODEGA } \\
\text { GENERAL }\end{array}$ & 0,00 & 0,00 & 3,00 & 255,36 \\
\hline
\end{tabular}

Fuente: Departamento de Almacén General del Gobierno Provincial de Manabí

A la cantidad de cuatro mil ciento treinta y nueve con 30/100, USD. 4.139,30 asciende el valor de faltante de inventario de la Bodega de Existencias a la fecha de corte 31 de julio de 2020.

A la cantidad de dos mil trescientos treinta y cuatro con 96/100, USD. 2,334.96 asciende el valor sobrante de inventario de la Bodega de Existencias a la fecha de corte 31 de julio de 2020.

Las Bodegas de Existencias de Medicinas y Productos farmacéuticos, y la Bodega de Aceites y Lubricantes se encuentran conciliadas.

La Bodega de combustible presentó un faltante de 887 galones de combustible Extra con etanol industrial por el valor de USD 1,948.45.

La Bodega General presentó un faltante de 3 canecas de aceite RANDO HYD OIL HD 46 que asciende a USD 255.36.

Se encontraron bienes caducados en existencias por USD 55.592,53 
De acuerdo a las actividades planificadas, se realizó la conciliación de saldos de las cuentas de bienes de larga duración e inventarios, y se realizaron los ajustes correspondientes tomando en consideración el saldo de corte del proceso de control interno constatación física de bienes y existencias.

Se anexó al informe de constatación física el listado de cuentas por cobrar tanto de bienes de larga duración, sujetos de control administrativo e inventarios para que se realicen los ajustes contables.

\section{Discusiones}

De la observación directa efectuada por el investigador, en el Gobierno Provincial de Manabí los inventarios se encuentran organizados contablemente y físicamente por bodegas para un mayor control, esto es una buena práctica porque al momento de realizar el control de constatación física la conciliación es por bodega, y de esta manera se conoce exactamente donde se encuentran tanto físicamente como contablemente dichos inventarios, permitiendo una adecuada conciliación, ya que al existir una novedad de faltante o sobrante se identifica con facilidad, esto se afirma si se toma como referencia lo señalado en el Reglamento General Sustitutivo para la Administración, Utilización, Manejo y Control de los Bienes e Inventarios del sector público en el artículo 54, expedido por la Contraloría General del Estado (2020), que "los resultados de la constatación física serán enviados a la Unidad Administrativa para fines de consolidación".

En lo que corresponde a los inventarios de la Bodega de Desarrollo Social que contiene fármacos, éstos deberían tener un control en el sistema Olympo en cuanto al lote, caducidad, fecha de elaboración, registro sanitario, de tal como que exista un adecuado control interno sobre ellos y que al momento de la constatación física exista coincidencia tanto en lo físico como en lo registrado en el sistema, pues aquí se muestra la incidencia del control interno y del apoyo de las TICs en el control de los inventarios. Cuando la medicina está a 90 días de caducar se debe comunicar al proveedor para hacer el respectivo canje de la misma, sin embargo, el sistema Olympo no favorece estas alertas que brinden una seguridad del stock físico que se encuentra almacenado, por este aspecto el autor asume el concepto de inventarios señalado en la Norma Internacional de Información Financiera para pequeñas y medianas empresas. (International Financial Reporting Standard for Small and Medium-Sized Entities, 2017, p.84).

Con respecto a la Bodega de Combustibles y General corresponden a una adecuada forma de control adoptada por la entidad, ya que en aun cuando por la naturaleza de los inventarios no ingresen físicamente a la bodega o inventario institucional deben ser controlados como tal observando la legislación vigente, situación que ocurrió con el material pétreo, diesel, gasolina extra y súper. 
En lo que se refiere a la aplicación de encuestas, el personal no ha sido capacitado sobre las Normas de Control Interno y en particular las que se aplican para el proceso de constatación física, por lo que se han tomado criterios generales desde la normativa, pero no se han desarrollado procedimientos por escrito, y ante tal situación se desconocen las actividades y responsabilidades de los intervinientes en el proceso de control interno, ya que no se dejan documentada las fases de intervención, lo que no genera valor agregado y justificación a lo actuado.

En la fase documental, el cronograma y el plan de trabajo se constituyen en el principal punto de control, sin embargo se evidencia la responsabilidad de los intervinientes, puesto que el informe se emitió con fecha posterior a la considerada en el cronograma, y a esto la ausencia de la certificación de saldos de parte de la Dirección Financiera para su respectiva conciliación y tomar las acciones necesarias, razón ocurrida por el desconocimiento de normativa y por la falta de procedimientos para la constatación física. En las mismas Normas de Control Interno se expresa que los procedimientos se emitirán por escritos y que cada entidad deberá adoptar los necesarios para su aplicación.

\section{Conclusiones}

- Con los resultados obtenidos en esta investigación, se concluye que el control interno favorece la gestión de inventarios y bienes de larga duración con procedimientos para una clara percepción de efectividad, idoneidad y cumplimiento de las operaciones. El Gobierno Provincial de Manabí no cuenta con un procedimiento diseñado para el proceso de constatación física de inventarios y bienes de larga duración y control administrativo, razón por la cual se torna necesario definir lineamientos desde la planificación hasta los ajustes contables de los resultados obtenidos del proceso de control interno efectuado en cumplimiento de la normativa. Es por esto que se planteó la necesidad a la dirección de innovación y mejora continua de la institución de formular el flujo de actividades para realizar la constatación física de bienes e inventarios tomando en consideración los tiempos establecidos en la normativa vigente aplicable, y de esta forma responsabilizar a los funcionarios involucrados en el proceso, a fin de dejar constancia de lo actuado.

- Es importante que la institución fortalezca el sistema de control interno, y que éste permita un adecuado control de las actividades, el mismo que servirá de base para las acciones de control que efectúe el organismo de control, y por otro lado a aportar a una nueva imagen y visión institucional con calidad, eficiencia, ética, transparencia y responsabilidad, eliminando procesos o actividades que impiden el normal desarrollo de las mismas, innovando con capacidad de vincular la calidad a la Norma ISO 9000 y obtener una certificación internacional.

- Por otro lado, una vez emitido el informe de constatación física las instituciones 
a través de sus delegados deberán tomar las acciones necesarias con los bienes dañados, obsoletos, faltantes y sobrantes, perdidos y no presentados a fin de actualizar el inventario institucional.

\section{Referencias Bibliográficas}

Ablan, N., \& Méndez, Z.(2010). Los sistemas de control interno en los entes descentralizados estadales y municipales desde la perspectiva COSO. Visión Gerencial, (1),5-17. ISSN: 1317-8822.

Aguilar, M. (2016). Metodología de la investigación.

Alana, T., Morán, G., \& Sanmartín, G. (2017). La auditoría ambiental en las Mipymes como herramienta de control interno en la gestión empresarial. Universidad y Sociedad, $9(1)$, 143-147. doi:/scielo.sld.cu/scielo.php?script=sci_arttext\&pid=S2218 36202017000100020\&lng=es\&tlng=es.

Arispe, C., Yangali, J., Guerrero, M., Lozada, O., Acuña, L., \& Arellano, C. (2020). La investigación científica: una aproximación para estudios de posgrado. Guayaquil: Universidad Nacional del Ecuador.

Cherres, C. P. P., Saá, M. J. M., \& Chaluisa, S. F. C. (2020). Pedidos y transporte: Una unidad estratégica de estudio en indicadores logísticos de la nueva era. Revista Arbitrada Interdisciplinaria Koinonía, 5(9), 468-488.

Contraloría General del Estado. (2009). Normas De Control Interno De La Contraloría $\begin{array}{llll}\text { General Del Estado. } & \text { Ultima, } & 79 .\end{array}$ http://www.oas.org/juridico/PDFs/mesicic5_ecu_ane_cge_12_nor_con_int_40

Contraloría General del Estado. (2020). Reglamento General Sustitutivo para la administración, utilización, manejo y control de los bienes e inventarios del sector público. Quito: Registro Oficial Suplemento 388 de 14-dic.-2018.

Firma Actualícese. (2017). COSO, control interno con un enfoque internacional. doi:https://actualicese.com/coso-control-interno-con-un-enfoque-internacional/

Fuente, C. (2004). Cálculo del tamaño de la muestra. Matronas Profesión, 5.

Gamboa, J., Puente, S., \& Vera, P. (2016). Importancia del control interno en el sector público. Revista Publicando, 3(8), 487-502.

International Financial Reporting Standard for Small and Medium-Sized Entities. (2017). Norma Internacional de Contabilidad 16: Propiedades, Planta y Equipo. 
International Financial Reporting Standard for Small and Medium-Sized Entities. (2017). Norma Internacional de Información Financiera para Pequeñas y Medianas Entidades (NIIF para las PYMES). London: IFRS.

Mendoza, W., Delgado, M., García, T., \& Barreiro, I. (2018). El control interno y su influencia en la gestión administrativa del sector público. Dominio de Las Ciencias, 4(4), 206-240. file:///C:/Users/RIOSNETE/Downloads/DialnetElControlInternoYSuInfluenciaEnLaGestionAdministra-6656251.pdf

Ministerio de Economía y Finanzas. (2016). Normativa de Contabilidad Gubernamental.

Montiel, M.E., Montiel, C.C. \& Montiel Sandoval, O.A. (2017). ¿La implementación del control interno fortalece la gobernabilidad en las alcaldías municipales de Colombia? Administración \& Desarrollo, 47(1), 97-117

Novo, C. (2016). Procedimiento de control interno para el ciclo de inventario. 3C Empresa: Investigación y Pensamiento Crítico, 5(4), 32-40. https://doi.org/10.17993/3cemp.2016.050428.32-40

Organización Internacional de las Entidades- INTOSAI., (2013). Compendio de Normas Internacionales de Auditoría Gubernamental propuestas para desarrollar el Marco de Normas Profesionales del SNF Versión: 1 de marzo de 2013. www.issai.org.

Otzen, T., \& Manterola, C. (2017). Técnicas de Muestreo sobre una Población a Estudio. Int. J. Morphol, 227-232.

Ponce Rosas, R., Jiménez Galván, I., Baillet Esquivel, L., \& Landgrave Ibáñez, S. (mayo de 2015). Diseño metodológico y tipo de estudios.

Real Academia Española. (2020). Diccionario de la lengua española.

Rivas, G. (2011). Modelos contemporáneos de control interno. Fundamentos teóricos. Observatorio Laboral Revista Venezolana, 4(8),115-136. ISSN: 1856-9099. Disponible en: https://www.redalyc.org/articulo.oa?id=219022148007

Ruiz, M., \& Hernández, M. (2007). El control en las organizaciones: un marco de estudio. Conocimiento, innovación y emprendedores: Camino al futuro, 33663382.

Universidad de san martín de porres. (2020). Metodología de la investigación. Ciudad Universitaria Santa Anita: Unidad Académica de Estudios Generales.

Urquizo, A. (2014). El Control Administrativo y el cumplimiento de objetivos en la Industria y Textiles Pequeñín Cía. Ltda. Ambato: Universidad Técnica de Ambato. 
Vásquez, O. P. (2016). Visión integral del control interno. Contaduría Universidad De Antioquia

doi:https://revistas.udea.edu.co/index.php/cont/article/view/328434

\section{Ciencia LDigital}

El artículo que se publica es de exclusiva responsabilidad de los autores y no necesariamente reflejan el pensamiento de la Revista Alfa Publicaciones.

\section{Ciencia
Digital
$\varepsilon$ dituolal}

El artículo queda en propiedad de la revista y, por tanto, su publicación parcial y/o total en otro medio tiene que ser autorizado por el director de la Revista Alfa Publicaciones.
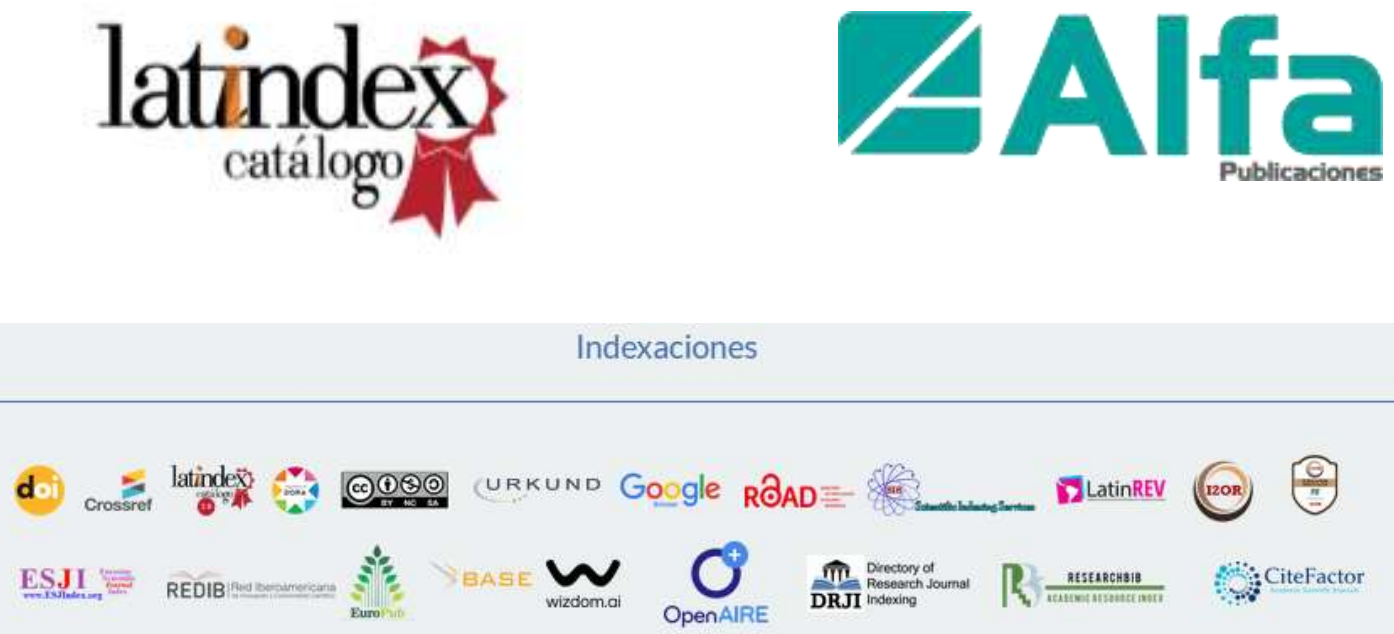